\title{
0 marketing de relacionamento através da Gestão de Relacionamento com o Cliente (CRM) como estratégia de fidelização.
}

(Relationship marketing through Customer Relationship Management (CRM) as a loyalty strategy.)

\author{
Ana Vivian Sarmento Silva \\ Eduardo Ângelo Marques \\ Maurício Vulcão da Silva \\ (UNINASSAU) Belém-Pará. \\ Sidney Gomes Viana \\ (SCA) Grupo GPD Belém-Pará.
}

Fecha recepción: 01-10-2017

Páginas 107-118

Fecha aceptación: 01-12-2017

\section{Resumo.}

Este estudo buscou definições sobre as estratégias utilizadas por empresas de diversos setores do mercado para criar relacionamentos à longo prazo com seus clientes, utilizando o marketing de relacionamento como base de estudo do comportamento do consumidor numa gestão de relacionamento que busca compreender as reais necessidades dos clientes potenciais. A pesquisa fundamentou-se num estudo bibliográfico com enfoque qualitativo do tipo descritivo. A coleta dos dados foi junto a autores consagrados sobre o marketing. Contudo, a qualidade e 0 atendimento mostrará 0 valor que a empresa tem em conquistar e satisfazer o cliente, mesmo ao escolher e dar preferência aos serviços e ou à marca, ocorrerá reciprocidade de valores entre a empresa que se pré dispõem em entregar 0 produto necessário e, o cliente a confiança na qualidade do que está adquirindo.

Palavras chave: cliente; satisfação; fidelização; relacionamento; marketing

\section{Abstract.}

This study sought definitions on the strategies used by companies from various market sectors to create long-term relationships with their customers, using relationship marketing as the basis of study of consumer behavior in a relationship management that seeks to understand the real needs of customers potential. The research was based on a bibliographic study with qualitative approach of the descriptive type. The collection of the data was with established authors about marketing. However, the quality and service will show the value that the company has in conquering and satisfying the customer, even when choosing and giving preference to the services and or the brand, there will be reciprocity of values between the company that pre-dispose in delivering the necessary product and, the customer to trust in the quality of what is acquiring.

Key words: customer; satisfaction; loyalty; relationship; marketing 


\section{1.-Introdução.}

Este artigo aborda o marketing de relacionamento através do Customer Relationship Management CRM (Gestão de Relacionamento com o Cliente) como estratégia de fidelização. Por isso o foco passa a ser conquistar o cliente e manter um relacionamento longo e saudável, que para Kotler e Armstrong (2007) é muito favorável já que em média pode custar de cinco a dez vezes mais atrair um novo cliente do que manter um atual satisfeito.

Diante do desafio de manter o cliente fiel utilizou-se o marketing de relacionamento através do Customer Relationship Management, CRM (Gestão de Relacionamento com o cliente) para compreender como identificar, conquistar e conseguir fidelizar os clientes potencias.

A competitividade é preocupante e os clientes estão cada vez mais exigentes, por isso, as empresas precisam utilizar o marketing para atrair e manter a clientela o que corrobora Kotler (2007) afirmando que o marketing é uma forma de entender e satisfazer as necessidades do cliente criando valor e construindo relacionamentos com a clientela para obter vantagem competitiva. Assim sendo, a problematização que destaca: Como utilizar o CRM para sair à frente da concorrência?

Para nortear a pesquisa o objetivo geral que busca: investigar como garantir a fidelização do cliente utilizando o CRM e como objetivos específicos apontar como as empresas utilizam de forma assertiva o marketing de relacionamento, demonstrar a importância do marketing de relacionamento nas empresas e elencar cases bemsucedidos através do marketing de fidelização.

\section{2.-O marketing como ciência de fidelização.}

Teoria base está centrada no marketing como função organizacional com suas variáveis, envolvendo criação, comunicação e aplicabilidade. Já que o marketing é denominado a ciência do consumo e é ele que nos ajuda a compreender o que leva o consumidor a ter satisfação e fidelização por um serviço ou produto.

Para alcançar este resultado recorreu-se ao Customer Relationship Management CRM (Gestão de Relacionamento do Cliente) braço do marketing que trata especificamente de dados utilizados para criar estratégias previamente planejadas e aplicadas afim de conseguir a fidelização dos clientes.

0 autor que transita importantemente pelo tema inicialmente e até os tempos contemporâneos é Phillip Kotler que contribui sobre a temática afirmando que dentro do processo de atrair e manter clientes, o ponto de partida são os possíveis clientes (os que presumivelmente poderão comprar). Em seguida, a empresa determina quais são os clientes potenciais, os quais espera reverter em clientes eventuais, depois em clientes regulares e logo em clientes preferenciais (clientes tratados excepcionalmente bem).

Kotler (2000) afirma que a chave para se gerar um grande nível de fidelização é entregar um alto valor para o cliente, onde valor é o conjunto de benefícios que os 
clientes esperam de um determinado produto ou serviço. Assim, surpreendendo as expectativas do cliente este por sua ver cria valor à marca, produto ou serviço que Ihe foi oferecido.

\section{2.-1.-Marketing de relacionamento e fidelização.}

O marketing está em nosso mundo há décadas, mas só a partir dos anos setenta com o marketing de massa (todos os clientes são iguais) passou a ser levado em consideração, entretanto, com a evolução tecnológica que houve no mundo e consequentemente em nossa sociedade em geral o marketing também evoluiu e hoje é considerado uma ciência.

Antes desta ciência chegar a ser o que representa hoje para o mercado e o que pode se tornar futuramente devemos levar em consideração que ela depende da sociedade mundial pois a essência do marketing é o ser humano. 0 marketing é a intenção de entender e atender o mercado como aborda Richers (1981), ele já estava mostrando que no futuro o foco seriam as pessoas e não o produto ou serviço.

Mais por alguma razão as indústrias continuavam com o foco no produto e usavam 0 marketing para publicidade na televisão e ofertas na internet. Sendo assim, as pessoas tinham uma ideia errônea sobre a essência do marketing, com isso, pode-se presumir que sempre haverá alguma necessidade de oferecer algum produto ou serviço, entretanto, a meta do marketing não é tornar a venda supérflua, mas sim conhecer e entender tão bem o consumidor que o produto ou serviço se adapte ao determinado cliente e acabe se vendendo sozinho, contribui Drucker (1992).

Então, a partir dos anos noventa passou-se a usar o marketing de relacionamento onde existem várias estratégias de como chegar a esse paradigma de se relacionar com o cliente, uma delas é o Customer Relationship Management CRM (Gestão de Relacionamento com o Cliente) que analisa dados dos consumidores para planejar e oferecer produtos e serviços adequados aos seus clientes.

De que forma podemos aplicar essa ciência em qualquer segmento no mercado oferecendo um produto ou serviço em função de uma determinada lucratividade? Primeiramente a empresa tem que entender que o marketing se relaciona com toda a cadeia de indivíduos que tem relação direta ou indireta com a empresa e com um único pensamento aparente, que é como podemos aumentar 0 nível de relacionamento com o cliente.

Dessa forma entendemos que o marketing de relacionamento como definiu Kotler (2000), deve ser compreendido como uma estratégia de mercado, onde o foco principal é sempre o cliente mas para que isso aconteça de maneira sucinta deve-se manter um relacionamento de confiança "ganha-ganha" à longo prazo com os consumidores, fornecedores e colaboradores, com isso, os clientes potenciais e fiéis à marca ou empresa precisam receber atenção continua.

Berry (1995) sugere três níveis de marketing de relacionamento que dependem da relevância dos benefícios do relacionamento para o cliente e que podem levar a fidelização (Quadro 2). 
Quadro 2: Três níveis de marketing de relacionamento

\begin{tabular}{|c|c|c|c|}
\hline Nível & $\begin{array}{l}\text { Níveis de relacionamento } \\
\text { com o cliente }\end{array}$ & $\begin{array}{l}\text { Grau de } \\
\text { atendimento } \\
\text { customizado }\end{array}$ & $\begin{array}{c}\text { Potencial para } \\
\text { explorar vantagem } \\
\text { competitiva } \\
\text { sustentável } \\
\end{array}$ \\
\hline 1 & $\begin{array}{l}\text { Financeiro: } \\
\text { Compras pelo valor do } \\
\text { produto }\end{array}$ & Baixo & Baixo \\
\hline 2 & $\begin{array}{l}\text { Social: } \\
\text { Possui um relacionamento } \\
\text { pessoal com o cliente }\end{array}$ & Médio & Médio \\
\hline 3 & $\begin{array}{l}\text { Estrutural: } \\
\text { O relacionamento } \\
\text { transcende o fator empresa } \\
\text { cliente, podendo ser } \\
\text { considerado como parceria }\end{array}$ & Médio para alto & Alto \\
\hline
\end{tabular}

Fonte: A própria pesquisa.

No primeiro nível de relacionamento, são oferecidos incentivos financeiros para que 0 cliente permaneça fiel. Prática essa comum em programas de desconto para compras repetidas.

No segundo nível, o relacionamento se sustenta por meio de barreiras sociais que dificultam o rompimento do relacionamento entre as partes envolvidas, tais como a personalização e a customização do relacionamento. Por exemplo: comunicações regulares com os clientes fazendo que se sintam próximos provendo a continuidade do serviço pelo mesmo representante de vendas e aumentando a qualidade do serviço por meio de atividades educacionais ou de entretenimento, tais como treinamentos, seminários, festas etc.

No terceiro nível, o marketing de relacionamento se sustenta em soluções estruturais para importantes problemas dos clientes. Quando o marketing de relacionamento oferece valores agregados que são difíceis ou caros para o cliente e que não são facilmente disponíveis em outro local, cria-se um forte fundamento para a manutenção do relacionamento.

Algumas das empresas mais bem-sucedidas estão elevando expectativas e encontrando formas de garantir seu desempenho superior por meio da satisfação do cliente. Por isso, saber identificar a ocorrência de eventos que determinam mudanças nas necessidades passa a ser fundamental para, cada vez mais, participar da vida de cada um dos clientes que a empresa tem como objetivo atender. (KOTLER, 2000, p.58)

Mackenna (1991) apresenta uma proposta de marketing adaptativo que enfatiza a sensibilidade, flexibilidade e elasticidade. Onde, a sensibilidade parte da percepção da empresa em conhecer e entender 0 ambiente através dos grupos de usuários que 
dão feedback aos pesquisadores fornecendo dados sobre as escolhas dos consumidores em tempo real.

A flexibilidade parte da capacidade da empresa de se estruturar tanto na organização quanto na operacionalização por intermédio do feedback obtido e assim aproveitar as oportunidades que surgem.

Em relação a elasticidade, vem demonstrar a capacidade que a empresa tem de aprender com erros passados fazendo com que estes não se repitam no futuro prejudicando a empresa.

Com todos esses benefícios oferecidos pela empresa há uma grande chance de 0 cliente ser fidelizado por um longo período atribuindo a empresa grandes vantagens competitivas como o aumento das vendas, pois um cliente fiel acaba comprando sempre mais. E também os custos da empresa são menores pois, segundo Kotler (2007) a empresa gasta dez vezes mais para atrair um novo cliente do que manter um cliente satisfeito e em função disso ele se torna um percursor de suas ofertas, do atendimento, do produto e se tornando um multiplicador da marca da empresa.

Assim, pode-se observar, através das definições citadas e de outras estudadas para esse trabalho, um consenso sobre o que é Marketing de Relacionamento que se baseia em estratégias de serviço em função do cliente partindo de toda a empresa, buscando novas formas de comunicação para estabelecer um relacionamento profundo e duradouro com o cliente, tornando-os fiéis. Trazendo aumento da retenção e lealdade dos clientes estabelecendo relacionamentos a longo prazo, comprando mais e com maior frequência.

Outro benefício compreendido e já citado é a maior lucratividade da empresa em função dos custos menores para manter seus clientes e a redução do custo de vendas já que os clientes já existentes reagem melhor ao marketing, nesse caso, para atingir novos clientes os custos são maiores do que manter o relacionamento com os já existentes.

\section{2.-Gestão de relacionamento com o cliente (CRM).}

Zenone (2007) afirma que as empresas enfrentam problemas mercadológicos a partir das necessidades e expectativas criadas no novo cenário, obrigando os especialistas em marketing a estarem monitorando o mercado constantemente. Assim, passam a conhecer as características e necessidades que passam por alterações constantes, podendo tomar as decisões corretas a todo momento.

Ainda sobre as mudanças ocorridas no mercado, Zenone (2007) informa que em geral, as empresas possuem muitos dados (não informações) armazenados (não organizados), que não são analisados como forma de se obter vantagem e acabam se tornando irrelevantes, assim, esse novo enfoque do marketing permite um profundo conhecimento dos clientes e do mercado, buscando atender efetivamente aquilo que precisa ou deseja cada segmento do mercado ou cliente individualmente. 
Para atingir esses objetivos a empresa precisa de mudanças no seu processo organizacional. Para Etzel (2001), para se conhecer e construir um relacionamento a longo prazo com o cliente a empresa deve definir quais os clientes potenciais que irá trabalhar, para dar continuidade deve utilizar um sistema de gerenciamento (CRM) para as informações dos clientes e 0 atendimento precisa ser diferenciado transformando vendedores em gerentes de clientes preparados para aprimorar a relação com os consumidores por meio de informações relevantes.

Para que isso ocorra é necessário o comprometimento de todos os setores da organização, Zenone (2007) afirma, que o relacionamento não deve ser tratado como uma atividade de um departamento ou um conceito isolado, assim, com a participação de todos os membros do processo produtivo há o aumento do valor do relacionamento para o cliente final utilizando estratégias direcionadas.

Existem dois conceitos que determinam um papel importante para as ações do marketing de relacionamento, no estudo em questão iremos abordar o CRM (Customer Relationship Management).

Do ponto de vista tecnológico, CRM envolve capturar os dados do cliente ao longo de toda a empresa, consolidar todos os dados capturados interna e externamente em um banco de dados central, analisar os dados consolidados, distribuir os resultados dessa analise aos vários pontos de contato com o cliente e usar essa informação ao interagir com o cliente por meio de qualquer ponto de contato com a empresa. (Peppers E Rogers, 2000, p.35)

Facilitando a teoria vista, Zenone (2007) afirma que o CRM busca melhorar o relacionamento da empresa com o mercado-alvo propiciando benefícios mútuos, satisfazendo as necessidades do mercado e trazendo os resultados esperados pela empresa.

Segundo Brown (2001), o CRM não é nem um conceito nem um projeto, é uma estratégia de negócios que visa entender e antecipar as necessidades dos clientes atuais e potenciais de uma organização.

Como visto nas definições anteriores fica claro que buscar compreender as necessidades dos clientes (mercado-alvo) e garantir melhorias continuas no relacionamento entre a empresa e o cliente são fatores fundamentais para a criação de valor entre ambos ocasionando 0 aumento da probabilidade de fidelização.

Baseado nas teorias de Zenone (2007), o conceito de CRM como vai ser visto no quadro 1 é dividido em analítico onde se determina quais são os clientes que devem ser tratados de forma personalizada, esses clientes são definidos por meio de dados que revelam quem são os clientes e suas características.

O CRM colaborativo é aquele onde estão todos os meios de contato interativo com o cliente. Como e-mail, fax, internet e etc. E o CRM operacional que é onde a maioria das empresas está focada, consiste na força de vendas e centros de atendimento ao 
cliente (call centers), sites de comercio eletrônico e sistemas de pedidos otimizando processos e organizando o fluxo de atendimento gerando qualidade e agilidade.

Quadro 1: Os tipos de CRM, seus objetivos e principais funções.

\begin{tabular}{|c|c|c|}
\hline - & Objetivo & Funções \\
\hline CRM = ANÁLITICO & $\begin{array}{l}\text { Determinar quais os } \\
\text { clientes a serem } \\
\text { tratados de forma } \\
\text { personalizada. }\end{array}$ & $\begin{array}{l}\text { Utilizar todos os } \\
\text { dados de clientes } \\
\text { possíveis. } \\
\text { Transferir o foco do } \\
\text { produto para o cliente. }\end{array}$ \\
\hline CRM = COLABORATIVO & $\begin{array}{l}\text { Interagir com o cliente } \\
\text { utilizando ferramentas } \\
\text { de contato. }\end{array}$ & $\begin{array}{l}\text { Utilização de e-mail, } \\
\text { fax e internet para } \\
\text { aumentar a interação } \\
\text { entre a empresa e o } \\
\text { cliente. }\end{array}$ \\
\hline CRM = OPERACIONAL & $\begin{array}{l}\text { Otimizar os processos e } \\
\text { organizar os fluxos de } \\
\text { atendimento. }\end{array}$ & $\begin{array}{l}\text { Garantir qualidade e } \\
\text { agilidade no } \\
\text { atendimento. }\end{array}$ \\
\hline
\end{tabular}

Fonte: A própria pesquisa.

Brown (2001) destaca a importância da tecnologia que fornece suporte ao modelo de CRM e possibilita o desenvolvimento de uma infraestrutura estratégica com informações eficientes, tudo com o objetivo de tornar, para os melhores clientes, a relação com a empresa algo fácil e conveniente, buscando sua satisfação e fidelidade. A empresa de posse desses dados tem a possibilidade de surpreender as expectativas do cliente.

Os clientes são peças-chave do funcionamento do CRM, de modo que, para a empresa é preciso conhecer quem é o cliente, qual seu comportamento, quais clientes são rentáveis, quais são maus pagadores e o mais importante: entender que os clientes não nascem fiéis, devem ser conquistados. Peppers e Rogers (2000) afirma, com a utilização dessas ferramentas é possível identificar os clientes de maior e menor valor para a empresa e desenvolver um tratamento diferenciado buscando a estratégia base do CRM que é a personalização do atendimento.

2.3.-O Marketing de relacionamento (CRM) aplicado a programas de fidelização

a): km de vantagens Ipiranga

$\mathrm{O} \mathrm{Km}$ de Vantagens é o programa de fidelidade dos Postos Ipiranga. A cada vez que o cliente abastece ou compra produtos nos postos credenciados, onde, 0 atendente realiza o cadastro apenas com o CPF do cliente armazenando no banco de dados da empresa. Nesse contexto, percebe-se o uso do CRM que segundo Brown (2001) não é um conceito ou um projeto, mas uma estratégia de negócio.

Os postos Ipiranga oferecem produtos e serviços de forma dinâmica, com qualidade, conforto, comodidade, confiabilidade e benefícios. A cada vez que o cliente abastece 
seu veículo adquire uma pontuação que no futuro pode ser trocada por produtos, combustível, viagens e outras vantagens espalhadas por mais de 80 parceiros.

Neste artigo mostramos que o CRM e o marketing de relacionamento trabalham sistematicamente em conjunto, a exemplo da rede de postos Ipiranga que 0 utiliza com maestria. Mackenna (1991) afirma que é o marketing adaptativo que enfatiza a sensibilidade, flexibilidade e elasticidade, mostrando exatamente como é trabalhado o marketing de relacionamento dos postos Ipiranga, onde, além de serviços como troca de óleo, limpeza e vidros e atendimento diferenciado os clientes usufruem da rede de conveniência consumindo diversos produtos e acumulando pontos no programa de fidelização.

b): Meliuz

Tem por objetivo se tornar o melhor programa de fidelidade do Brasil, onde o cliente é recompensado em dinheiro e não por sistema de pontos.

Buscando facilitar a vida dos clientes e aumentar seus ganhos o programa trabalha desenvolvendo parcerias e novas tecnologias querendo conquistar a lealdade do cliente e recompensá-lo dia-a-dia. Kotler (2000) defende que o marketing de relacionamento de ser compreendido como uma estratégia de mercado onde o foco principal é sempre o cliente.

Entretanto, o foco desse projeto foi a insatisfação com os programas de fidelidade já existentes, pois o sistema de pontos possui dificuldades na hora de resgatar os pontos obtidos e na maioria das vezes não são suficientes para serem trocados por benefícios desejados pelos clientes. Desta forma, entendemos que não há no mercado preocupação com a evolução desses programas, pois se há um problema recorrente dentro dos programas de fidelidade oferecidos o mesmo já deveria ter sido levado em consideração pelas empresas buscando melhorá-lo.

Contudo, a empresa Meliuz inovou o sistema de pontos pelo sistema cashback que significa "dinheiro de volta", onde, o cliente ao realizar uma compra pelo site da Meliuz recebe diretamente na conta bancária uma porcentagem do valor da compra, podendo utilizar este da forma que quiser.

O sistema cashback vem inovar os conceitos de estratégias de recompensas que buscam fidelizar o cliente à empresa, oferecendo diversos serviços e parcerias de compra (varejistas), que além de destacar os diversos sites de venda pela internet (ecommerce), disponibiliza diversos descontos e o diferencial que ao invés de acumular pontos para trocar por produtos (aonde deve ter um número de pontos especifico), a devolução de parte do valor torna-se a vantagem necessária para passar na frente da concorrência.

Desta forma podemos ressaltar que alguns clientes não querem somente um "brinde" em troca de um serviço oferecido pela empresa. Berry (1995) sugere três níveis de marketing de relacionamento mostrados anteriormente, que dependem da relevância que o cliente vai ter em relação ao benefício oferecido, aplicando-os de forma correta buscando modos de beneficiar o cliente de uma forma simples e direta. 


\section{3.-Metodologia.}

Este estudo fundamentou-se na pesquisa bibliográfica, utilizando-se do método qualitativo do tipo descritivo, centrado no comportamento do consumidor e metodologicamente, trata-se de uma revisão bibliográfica com fontes primárias que "correspondem à "literatura primária". São as que se apresentam e são disseminados exatamente na forma com que são produzidos por seus autores" (Pinheiro, 2006).

Hernández Sampiere (2006): "quantitativo porque usa os dados já coletados buscando delimitar 0 que se pretende pesquisar, com a finalidade de estabelecer modelos de comportamentos. Assim, "os estudos descritivos, medem, avaliam ou coletam dados sobre diversos aspectos, dimensões ou componentes do fenômeno a ser pesquisado" (p. 101).

Para debater o tema recorreu-se aos autores que dominam o conteúdo desta peça entre eles citamos Barlow (1992), Kotler (2012); Zenone (2007); Brown (2001) e da Associação de Marketing Americana (AMA) 2010).

\section{4.- Discussão dos resultados.}

Para a discussão dos resultados buscou-se as principais idéias da teoria de cada autor para o debate um teórico.

\begin{tabular}{|l|l|}
\hline Autores & Definições \\
\hline Barlow (1992) & $\begin{array}{l}\text { Afirma que fidelidade é uma estratégia que identifica, mantem } \\
\text { e aumenta o rendimento dos melhores clientes (mercado-alvo) } \\
\text { em uma relação de valor agregado, interativo e centrado ao } \\
\text { longo prazo, ou seja, atingindo o mercado-alvo e superando as } \\
\text { expectativas gerando a criação de valor que irá levar a } \\
\text { fidelidade do cliente à marca. }\end{array}$ \\
\hline Kotler (2012) & $\begin{array}{l}\text { Afirma que para captar e manter seus clientes é necessário } \\
\text { selecionar seus mercados-alvo e garantir a criação, entrega e } \\
\text { comunicação de um valor superior gerando valor agregado à } \\
\text { marca e superando as expectativas dos clientes. }\end{array}$ \\
\hline Zenone (2007) & $\begin{array}{l}\text { Aponta a importância do reconhecimento do benefício total } \\
\text { percebido pelo cliente versus o recurso empregado para } \\
\text { realizar uma atividade para atender ou solucionar um } \\
\text { problema. }\end{array}$ \\
\hline $\begin{array}{l}\text { Associação de } \\
\text { Marketing } \\
\text { Americana } \\
\text { (AMA). }\end{array}$ & $\begin{array}{l}\text { Voltou-se para a fidelização do cliente, cases de fidelização e } \\
\text { descreve como o CRM pode ser utilizado na fidelização do } \\
\text { cliente. }\end{array}$ \\
\hline
\end{tabular}




\begin{tabular}{|l|l|}
\hline Brown (2001) & $\begin{array}{l}\text { antecipação que este estudo pretende contribuir com a ciência } \\
\text { revelando a importância de estudar de maneira planejada o } \\
\text { comportamento do consumidor, desta forma, antecipando as } \\
\text { satisfações dos seus desejos. }\end{array}$ \\
\hline
\end{tabular}

Fonte: A própria pesquisa.

No que diz respeito ao marketing de relacionamento e o CRM, percebe-se que todos os autores fizeram seus estudos dentro de empresas de grande porte com diversas variáveis.

No entanto, a essência de sua estrutura pode ser usada em qualquer empresa de variados ramos e tamanhos, desde que aplicado de forma correta pode ser usada até mesmo por profissionais não qualificados.

Ressalta-se também que essa ferramenta tem que ser trabalhada de forma continua em perfeita sintonia, por todos os envolvidos no processo buscando a entrega, para atender a demanda, bem como, para se relacionar da melhor forma com o cliente gerando valor a empresa levando-o à sua fidelização.

Os autores demonstraram a relevância da temática para entender 0 verdadeiro significado da fidelização, como um caminho para o diferencial no competitivo mercado.

\section{5.-Conclusão.}

Essa investigação buscou essas ferramentas para tentar alcançar o objetivo que é a fidelização do cliente utilizando o marketing de relacionamento junto com o CRM. No entanto, pode-se dizer que há mais eficácia na conquista do cliente e da fidelização do mesmo se for trabalhado em conjunto entre empresa, colaboradores e fornecedores de forma única em função do cliente. Já que o CRM se torna um espelho das necessidades dos clientes que permite ao gestor se antecipar e surpreender o cliente de maneira positiva.

Ainda, a ciência mostra como as empresas utilizam de forma assertiva o marketing de relacionamento, estreitando os laços com seus clientes direcionando ofertas de produtos e serviços específicos para suas necessidades. O CRM é uma ferramenta de extrema importância nessa estratégia pois ele deve conter todas as informações necessárias para mostrar como é esse cliente fazendo com que a empresa disponibilize o produto adequado a ele.

Uma vez que o mercado está cada vez mais amplo, competitivo e com muitas ofertas disponíveis, entretanto, como apresentado no artigo as empresas que utilizam dessas estratégias planejam cada passo utilizando o marketing de relacionamento e - CRM que com um amplo banco de dados obtém uma vantagem bem larga em relação a concorrência, pois as empresas que não trabalham com essas ferramentas não conseguem oferecer um produto diferenciado. 
Assim sendo, as empresas que trabalham de forma assertiva o marketing de relacionamento como os postos Ipiranga que tem o "km de vantagens" que concede pontos para o seu cliente que abastece em qualquer uma de suas franquias por todo o brasil, assim, com essa estratégia consegue agregar valor ao seu produto e fidelizando seus clientes pois eles não vendem somente combustíveis, conseguindo oferecer outros produtos e serviços ao mesmo tempo dando comodidade aos seus clientes.

Contudo, busca inovar os programas de fidelidade dando grandes avanços no mercado por colocar o cliente como prioridade é Meliuz, que tem o objetivo de ser o melhor plano de fidelidade do brasil onde seus clientes não acumulam pontos para troca de produtos e benefícios em empresas parceiras. A Meliuz oferece uma porcentagem em dinheiro a cada compra que o cliente faz no site.

Deste modo, percebe-se várias empresas que estão focando suas estratégias para a conquista do cliente, ou seja, tentando se relacionar cada vez mais com os clientes que ainda estão sem saber onde comprar seus produtos preferidos e serem atendidos de forma apropriada. Assim, esse artigo nos mostra como a empresa precisa agir para se tornar uma das maiores em seu seguimento.

Assim sendo, o marketing de relacionamento vem com a proposta de mostrar como podemos fazer mudanças dentro das empresas para melhoria da cultura organizacional, do conhecimento do tipo de consumidores que a frequentam, como podem ser abordados com ofertas de produtos e serviços e que estratégias podem ser montadas para um determinado cliente ou grupo de clientes com o mesmo perfil.

Enfim, o CRM com suas variáveis analítico, colaborativo e operacional vem com a proposta de coletar os dados pessoais sobre cada cliente trabalhando em sintonia com o marketing de relacionamento pois as estratégias lançadas pela empresa são em função dessas informações, por isso, o CRM é peça fundamental nessa estrutura de trabalho.

\section{6.-Referências.}

Associação de Marketing Americana (AMA). (2010). Marketing. São Paulo: Makron Books.

Barlow, R. (1992). Relationship Marketing: The ultimate in costumer services. London: Retail Control.

Berry, L.L. (1995). Relationship Marketing of Services, growing interest emerging perspectives. London: Journal of Academy Of Marketing Science. v.23, n.7, $55-70$.

Brown, S. (2001). CRM (Costumes Relationship Marketing): Uma ferramenta estratégica para o mundo e-business. São Paulo: Makron Books.

Etzel, M., W.et al. (2001). Marketing. São Paulo: Makron Books. 
Jales, C. (2008). Marketing de Relacionamento: A importância do marketing de relacionamento. Rio de Janeiro: Summus.

Kotler, P. (2000). Administração de Marketing; a edição do novo milênio. São Paulo: Prentice Hall.

Kotler, P., Armstrong, G. (2007). Princípios de Marketing. Tradução Cristina Yamagami; revisão técnica Dilson Gabriel dos Santos. 12. Ed. São Paulo: Pearson Prentice Hall.

Kotler, P.; Keller, K.L. (2012). Administração de Marketing; tradução Sonia Midori Yamamoto. Revisão técnica Edson Crescitelli, 14. ed. São Paulo: Person Education do Brasil.

Mackenna, R. (1992). Marketing de Relacionamento, estratégias bem-sucedidas para a era do cliente. Campus. Rio de Janeiro: Regis Mackenna.

Peppers, D. y Rogers, M. (2000). CRM Series Marketing 1 a 1: Um guia executivo para entender e implantar estratégias de Customer Relationship Management. São Paulo: Peppers and Rogers Group Brasil.

Ribeiro, A., H.et al. (1999). Marketing de Relacionamento como fator-chave de sucesso no mercado. Revista de Administração de Empresas (RAE). Recuperado de: www.rae.fgv.br/sites/rae.fgv.br/files/artigos/10.1590_5003475901999000100005.pdf.

Richers, R. (1981). O que é marketing. São Paulo: Brasiliense.

Sampiere, H.R. (2006). Metodologia de la investigación. México: McGraw-Hill Interamericana.

Zenone, L.C. (2001). Customer Relationship Management. Mudando a estratégia sem comprometer o negócio. São Paulo: Atlas. 